\title{
BMJ Open Active travel behaviour in the family environment: protocol for the mixed- methods cross-sectional ARRIVE study
}

\author{
Anne Kerstin Reimers (D) , ${ }^{1}$ Isabel Marzi, ${ }^{1}$ Franziska Beck (D) , ${ }^{1}$ Eliane Engels, ${ }^{1}$ \\ Denise Renninger, ${ }^{2}$ Adrian Buttazzoni, ${ }^{3}$ Claus Krieger, ${ }^{4}$ Yolanda Demetriou ${ }^{2}$
}

To cite: Reimers AK, Marzi I, Beck F, et al. Active travel behaviour in the family environment: protocol for the mixed-methods cross-sectional ARRIVE study. BMJ Open 2022;12:e056383. doi:10.1136/ bmjopen-2021-056383

- Prepublication history and additional supplemental material for this paper are available online. To view these files, please visit the journal online (http://dx.doi.org/10.1136/ bmjopen-2021-056383).

AKR and IM contributed equally.

Received 16 August 2021 Accepted 13 January 2022

Check for updates

(c) Author(s) (or their employer(s)) 2022. Re-use permitted under CC BY-NC. No commercial re-use. See rights and permissions. Published by BMJ.

${ }^{1}$ Department of Sport Science and Sport, Friedrich-AlexanderUniversitat Erlangen-Nurnberg, Erlangen, Germany

${ }^{2}$ Department of Sport and Health Sciences, Technical University of Munich, Munchen, Germany

${ }^{3}$ School of Planning, University of Waterloo, Waterloo, Ontario, Canada

${ }^{4}$ Department of Languages and Aesthetic Disciplines Education, Universität Hamburg, Hamburg, Germany

Correspondence to

Professor Anne Kerstin Reimers: anne.reimers@fau.de

\section{ABSTRACT}

Introduction Active travel is an important source of physical activity and a primary contributor to overall health among adolescents. To understand and promote active travel behaviour in adolescents, developing a more robust understanding of the predictors of active travel and its associated decision-making processes is needed. Situated within a theoretical socioecological framework for adolescent travel behaviour, the mixed-methods Active tRavel behavioR in the famlly enVironmEnt study aims to quantitatively assess the influence of several predictors of adolescent travel behaviour, and to qualitatively understand the associated decision-making processes of both adolescents and parents.

Methods and analysis Our mixed-methods approach will feature online surveys and semistructured interviews. The online questionnaire, developed in accordance with a theoretical framework of adolescent active travel, will examine adolescent travel behaviour with respect to four different destinations while controlling for multiple relevant individual, social and physical environment factors. To enable the comparison of adolescent and parental perspectives, the questionnaire will be answered by a representative sample of German adolescents (11-15 years old) and their parents. Our semistructured interviews, likewise framed based on the central tenets of the theoretical framework of adolescent active travel, will seek to explore the decision-making process of families regarding travel mode choice via conducting interviews with each member (ie, father, mother, adolescent). To investigate travel decision-making processes, adolescents and their parents will be invited to talk about trips they undertook using both active and passive transport modes during the last week. Thematic analyses will be conducted to highlight the central concerns, priorities and values of participants' decisionmaking processes.

Ethics and dissemination This study has received ethical approval from the ethics commission of the FriedrichAlexander-University Erlangen-Nuremberg. Study results will be disseminated at scientific conferences and published in peer-reviewed journals. Additionally, study findings will be made publicly available to relevant health, policy, and research stakeholders and groups.

\section{INTRODUCTION}

Regular physical activity is an important source of overall health, can decrease the risk of non-communicable diseases and is linked to improved mental health. ${ }^{1}$ Longterm health benefits of physical activity are

\section{Strengths and limitations of this study}

- The quantitative part of the Active tRavel behavioR in the famlly enVironmEnt study includes a large representative sample of German parents and adolescents from diverse neighbourhoods and regions and different socioeconomic backgrounds. However, the sample might not be representative of typical German travel behaviours as they result from many additional factors like urban infrastructure accessibility, family work arrangements and other sociodemographic factors (eg, vehicle ownership) that we are not able to control for in this study.

- Situated within a theoretical socioecological framework, multiple theoretically relevant predictors of adolescent active travel behaviour and different modes of transport to four distinct destinations will be assessed.

- Reliable and valid tools in the form of online surveys, which were developed based on the central tenets of a theoretical socioecological framework of adolescent active travel, will be used to assess adolescent active travel behaviour and its predictors.

- Semistructured interviews will seek to generate a novel and nuanced understanding of the familial decision-making processes regarding transport mode choices from both parental and adolescent perspectives.

- Limitations include the cross-sectional design, selfreport survey data and a lack of objectively measured physical environment characteristics.

well documented for children, adolescents ${ }^{23}$ and adults. ${ }^{4}$ However, concerning low levels of physical activity among children, adolescent $^{5}$ and adults ${ }^{6}$ in countries across the globe demands urgent action. The WHO has observed that current efforts to reduce global inactivity rates have been largely ineffective, and that more innovative and comprehensive approaches to promote physical activity are needed. ${ }^{7}$

Active travel, that is any form of humanpowered transportation (eg, walking, biking), as a daily routine (eg, trips to/from school) is a low-cost and widely accessible source of 
physical activity. ${ }^{8}$ But despite many potential benefits of active commuting, percentages of active commuters have declined in most countries. ${ }^{9-13}$ In Germany, like in many other countries, for example, only a significant minority of adolescents currently walk or cycle to school. ${ }^{9}{ }^{14-16}$ Recent nationwide data from the German MoMo Study showed that $17.7 \%$ of adolescent girls and $20.2 \%$ of adolescent boys regularly walk to school, while $21.5 \%$ of girls and $25.2 \%$ of boys cycle to school. ${ }^{9}$

To better understand adolescent travel mode decisions and travel behaviour, as well as to enable the development of evidence-based intervention programmes that promote active travel in adolescents, a more comprehensive analysis of the predictors of adolescent active travel and decision-making processes is warranted. At present, cross-sectional $^{17-20}$ and longitudinal ${ }^{162122}$ research has identified various individual-level and neighborhoodlevel factors related to adolescent active travel. However, while these studies and extant theoretical socioecological models ${ }^{23}$ and active travel frameworks ${ }^{24-27}$ have outlined that adolescent active travel is a multi-level phenomenon, little is known about the influence of family-level predictors of adolescent active travel behaviour, the decisionmaking processes within the family and especially about adolescent travel behaviour to non-school destinations.

One comparatively understudied influence of potential consequence regarding adolescent active travel behaviour is family environment predictors (eg, parental support, role modelling, availability of a bicycle). Although recent study confirms the importance of parental controls with respect to adolescent transport mode choice, ${ }^{28-30}$ comprehensive studies of family environment predictors of adolescent active commuting remain rather limited. ${ }^{31}$ To date, studies have largely focused on examining only singular elements of the family-level. For example, recent works have found safety aspects in terms of traffic safety and a child's own ability to travel safely and independently strongly influence parental decision making on transport mode, ${ }^{2829} 32$ and that some parents prefer car usage to spend time with their children. ${ }^{32}$ Other noted relevant factors in this regard include social norms and convenience, ${ }^{28} 32$ and parenting practices ${ }^{29}$ as significant individual predictors. In other cases, however, family environment influences are ambiguous. When examining the role of distance to school and its interaction with family-level factors, existing evidence is inconclusive: while one Swedish study ${ }^{32}$ revealed that parents chauffeured their teenagers to school regardless of distance, another from Canada ${ }^{28}$ found that transport mode choice was influenced by perceptions of travel time and distance to school. Ultimately, given this combination of a lack of comprehensive investigations and uncertainty in other areas, there is a need to more comprehensively (eg, examine the interaction of parent and adolescent perceptions) consider family environment influences of adolescent active travel.

Similarly, while existing literature has focused significantly on active travel to/from school, only a few studies have considered other highly frequented destinations. Trips to leisure facilities, shops or the homes of friends and relatives often represent as much or a greater proportion of all trips travelled by adolescents than school commutes. For example, in Germany, adolescents accumulate on average 2.8 trips taking $72 \mathrm{~min}$ and having a total distance of $29 \mathrm{~km} /$ day. ${ }^{33}$ Of these trips, school commutes account for $35.5 \%$ of trips, while $39.5 \%$ are made related to leisure activities, $14.5 \%$ are related to shopping and everyday activities and around $4 \%$ are made while accompanying adults/parents to other locations. Despite these documented trends, there is a relative dearth of knowledge pertaining to how this variety of daily trips to destinations other than school may contribute to adolescent health representing another important avenue for future study.

The dynamics and impacts of parental and adolescent decision-making processes on adolescent active travel is likewise relatively understudied. Perhaps most notably, little is currently known about how the perceived social and physical environment facilitators and barriers to active travel among parents may vary across diverse cohorts from various geographical regions and degrees of urbanisation. ${ }^{34} 35$ Furthermore, while many previous studies have focused on children, few have addressed active travel behaviour in adolescents. ${ }^{34}$ Moreover, previous studies have not considered adolescent active travel behaviour in the context of the differing perspectives and attitudes of multiple family members ${ }^{36}{ }^{37}$ resulting in most existing studies focusing exclusively on either youth or parental perspectives and neglecting the inter-relation of both perspectives. ${ }^{38}{ }^{39}$ Such a precedent is an important oversight given that in their comparative study of children and adolescents as well as parental barriers on active commuting to school, Aranda-Balboa $e t a l^{40}$ found that there are significant differences between adolescents' and parents' perspectives in terms of perceived social and environmental determinants of active travel.

To better understand and promote adolescent active travel there are a few important research opportunities to address, namely: family environment predictors of adolescent active travel, the value and impact of non-school commuting trips, and the influence of the decisionmaking processes of adolescents and parents regarding travel behaviour. The ARRIVE study (Active tRavel behavioR in the famIly enVironmEnt) aims to address these gaps and develop a more comprehensive understanding of adolescent active travel behaviour through conducting a theoretically informed, multicomponent and mixed-methods investigation of German adolescents and parents.

\section{METHODS AND ANALYSIS \\ Study design}

The ARRIVE study, a mixed-methods cross-sectional study, intends to generate novel insights regarding (1) a range of predictors of adolescent active travel by considering trips to four commonly frequented destinations 


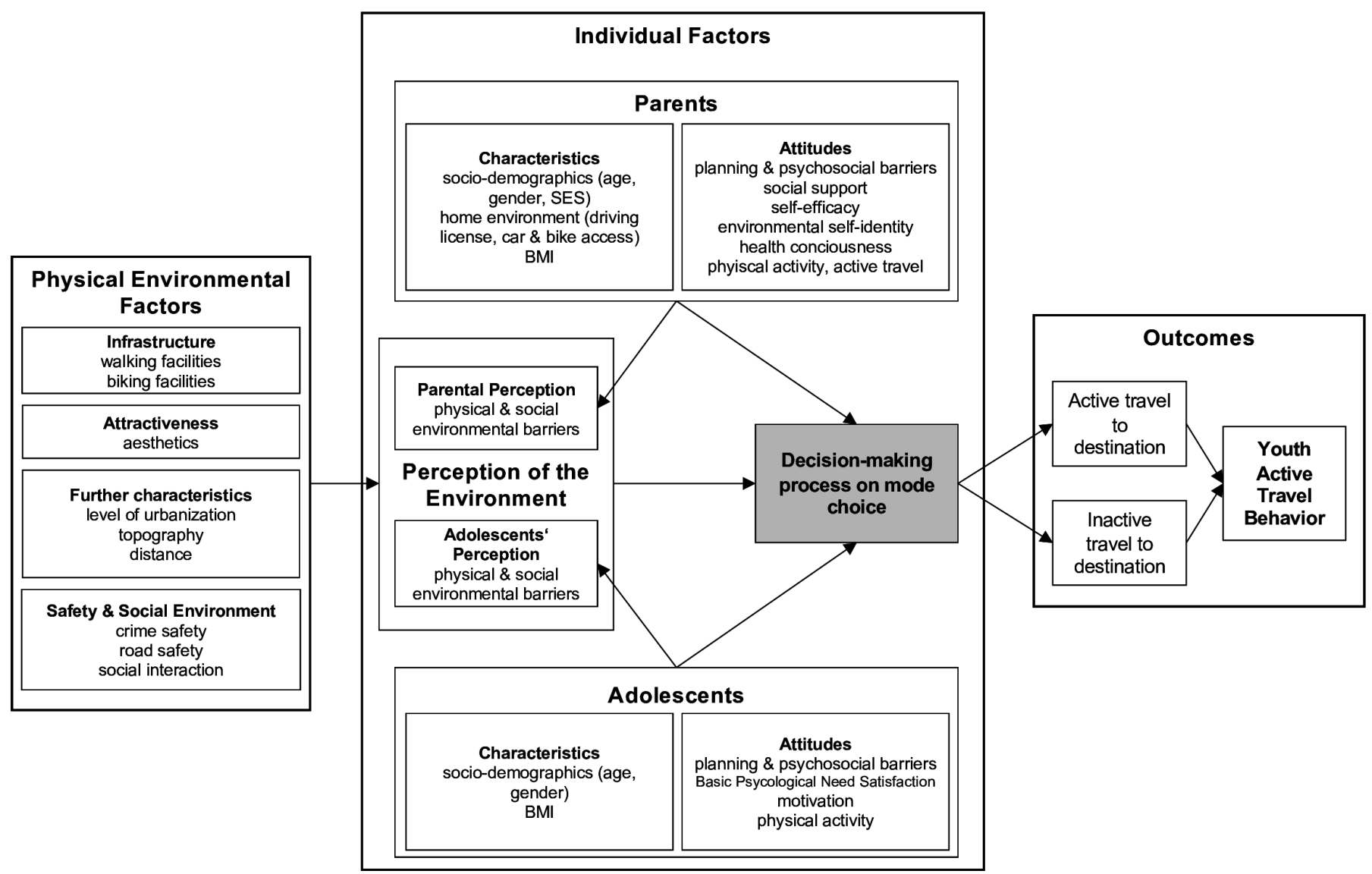

Figure 1 Theoretical framework for the ARRIVE study. BMI, body mass index; SES, socioeconomic status.

(travel to/from school/workplace, homes of friends and/or relatives, shops, leisure facilities), and (2) the intra-familial dynamics (ie, family context predictors and decision-making processes) that impact adolescent travel behaviours. ARRIVE's mixed-methods approach includes two complementary studies: quantitative online surveys and qualitative semistructured interviews. Both studies will collect data from multiple groups, specifically adolescents between 11-15 years old and their parents. Data collection for both studies will take place between June and December 2021.

\section{Theoretical framework}

We developed the ARRIVE study based on Panter et als 'Conceptual Framework for the Environmental Determinants of Active Travel in Children, ${ }^{27}$ (see figure 1). This framework serves as the study's theoretical foundation as it provides a multi-level outline of the predictors of adolescents' active travel based on the social-ecological model. ${ }^{1831}$ The framework considers physical (eg, neighbourhood design) and social (eg, crime) environment factors, as well as individual factors for both parents and youth (eg, sociodemographic and psychosocial variables, attitudes). In the ARRIVE study, we used these conceptual categories to identify relevant predictors of interest-eg, personal characteristics, attitudes, parental and adolescent perceptions of physical and social environment barriers-that will be examined in our statistical models in order to explore how they impact the main outcome (adolescent travel behaviour) in relation to the four commonly frequented destinations. ${ }^{41-43}$

\section{Quantitative study \\ Aims}

The overarching aim of the quantitative online survey will be to empirically evaluate the theoretical relationships proposed in Panter et als 'Conceptual Framework for the Environmental Determinants of Active Travel in Children'. ${ }^{27}$ In a first step, we will comprehensively describe travel behaviour in adolescents from Germany in dependence of destination and adolescents' sociodemographic characteristics. To systematically evaluate this theoretical model, our specific aims are threefold. First, we will seek to identify predictors of adolescent travel behaviour with respect to four different destinations in order to discern whether the predictive strength of these correlates varies between trip destinations. Second, we will aim to develop a more comprehensive understanding of adolescent transport mode choice in the family context by comparing parent and adolescent perspectives regarding transport mode choice. Third, we will investigate the moderating effects of several theoretically relevant sociodemographic characteristics (eg, sex/gender, migration background and degree of urbanisation) on adolescent travel behaviour. 


\section{Sampling strategy}

The survey makes use of an existing nationwide online panel (forsa.omninet) to which access is provided by Forsa, a leading organisation for public opinion polls. The recruitment for the survey will be conducted entirely offline via telephone interviews, so as to ensure that those lacking internet access are proportionately represented in the study. The panel contains people living in Germany and is representative of the German population regarding age, sex/gender, education and place of residence. Based on this panel, a sample of adults living together with adolescents aged 11-15 years old will be recruited. The sample will include roughly the same number of mothers and fathers. After giving informed consent to be contacted for the survey, participants will receive an invitation email with a link to the questionnaire.

As suggested by Bujang et $a l^{44}$ for observational studies with large population sizes, a minimum sample size of 500 is necessary to derive logistic regression analyses. By using real patient data, it was shown that a minimum sample size of 500 'is able to produce statistics that are nearly representative of the true values in the target population'. ${ }^{44}$ Thus, equivalent samples of parents $(n=500)$ and adolescents $(n=500)$ will complete the survey.

\section{Data collection}

Participants will be able to answer the online questionnaire using one of a tablet, smartphone or computer. The questionnaire includes two parts: a parent-focused section, and an adolescent-focused section. After answering their portion of the questionnaire, parents will be asked to provide the link to their adolescent or, if there is more than one adolescent in this age group in the family, to one randomly selected adolescent. To this end, parents who have multiple potential participants in their family will be instructed to select the adolescent whose first letter of their first name appears the earliest in the alphabet to fill out the adolescent portion of the survey. The survey is anticipated to take about $15 \mathrm{~min}$ to complete for adolescents and parents together.

\section{Measures}

To cover all relevant constructs, an online questionnaire has been developed based on already existing scales (that were partly translated into German), modified scales and additional single item questions. The selection of scales and questions were derived from the central tenets of the theoretical framework; all constructs mentioned in figure 1 will be assessed via adolescent and parent selfreports. Based on a literature search on activity settings of adolescents, four destinations adolescents frequently visit and which are the most popular places for adolescents in the walkable neighbourhood have been selected to assess travel behaviour in youth. ${ }^{41} 42456$ A detailed description of all measures applied in the online questionnaire for parents and adolescents is provided in table 1.
Data analysis

\section{Descriptive analysis}

Data analysis will include descriptive statistics, an examination of normally distributed data and examinations of the homogeneity of variance. Descriptive statistics will include means $(\mathrm{M})$ and $\mathrm{SD}$ for continuous variables, and frequencies $(\%)$ for categorical variables (eg, boys and girls and mothers and fathers). Frequency distribution of transport mode for each destination will be calculated separately for boys and girls. To examine internal consistencies of the adapted scales, Cronbach's alpha will be calculated with the respective values indicating excellent $>0.9$, good $>0.8$, acceptable $>0.7$, questionable $>0.6$, poor $>0.5$ and unacceptable $<0.5$ fit. $^{47}$

Outcome measures will consist of a categorical variable representing the different transport modes (eg, walking, cycling, driving) per destination, a dichotomous variable (passive vs active transport mode) for each destination, and an overall score of active transport including all destinations. This overall score will be calculated based on the proportion of active trips in relation to all reported trips resulting in an interval scaled variable with values between 0 (all trips passive) to 1 (all trips active).

\section{Aim 1: description of travel behaviour in adolescents from Germany}

Differences in transport mode choice and predictor variables between different groups (eg, age, sex/gender) will be calculated using t-tests and analysis of variance for continuous variables, and $\chi^{2}$ for categorical variables. For example, differences in transport mode choice between boys and girls and adolescents living in different regions with different degrees of urbanisation (cities, mediumsized towns, small towns, rural areas) will be calculated using Pearson- $\chi^{2}$-test and post hoc analysis ${ }^{48}$ as well as the comparison of transport mode across destinations according to parental sex/gender (mothers and fathers). To identify differences in travel distance between transport modes one-way analysis of variance will be calculated.

\section{Aim 2: identifying predictors of adolescent travel behaviour}

Multinomial (different transportmodes) and binary (active vs passive travel) logistic regression models controlling for multiple relevant sociodemographic variables will be used to identify predictors of adolescent active travel. Due to the heterogeneity of outcome measures, separate logistic regression analyses will be conducted for each destination using the dichotomous variables of transport mode choice as dependent variable, the individual, social and physical environmental variables as predictors. In all analyses, sociodemographic factors (eg, age, education) will be included as confounders. Adjusted odds ratio and 95\% CIs will be reported. For some analyses, the overall score of active travel will be used as categorical, dependent variable, for example, to assess the effect of the motivational regulations on active travel behaviour in adolescents. The regression analysis will either be performed for the whole sample or due to theoretical assumptions separately for male and female adolescents to account for 


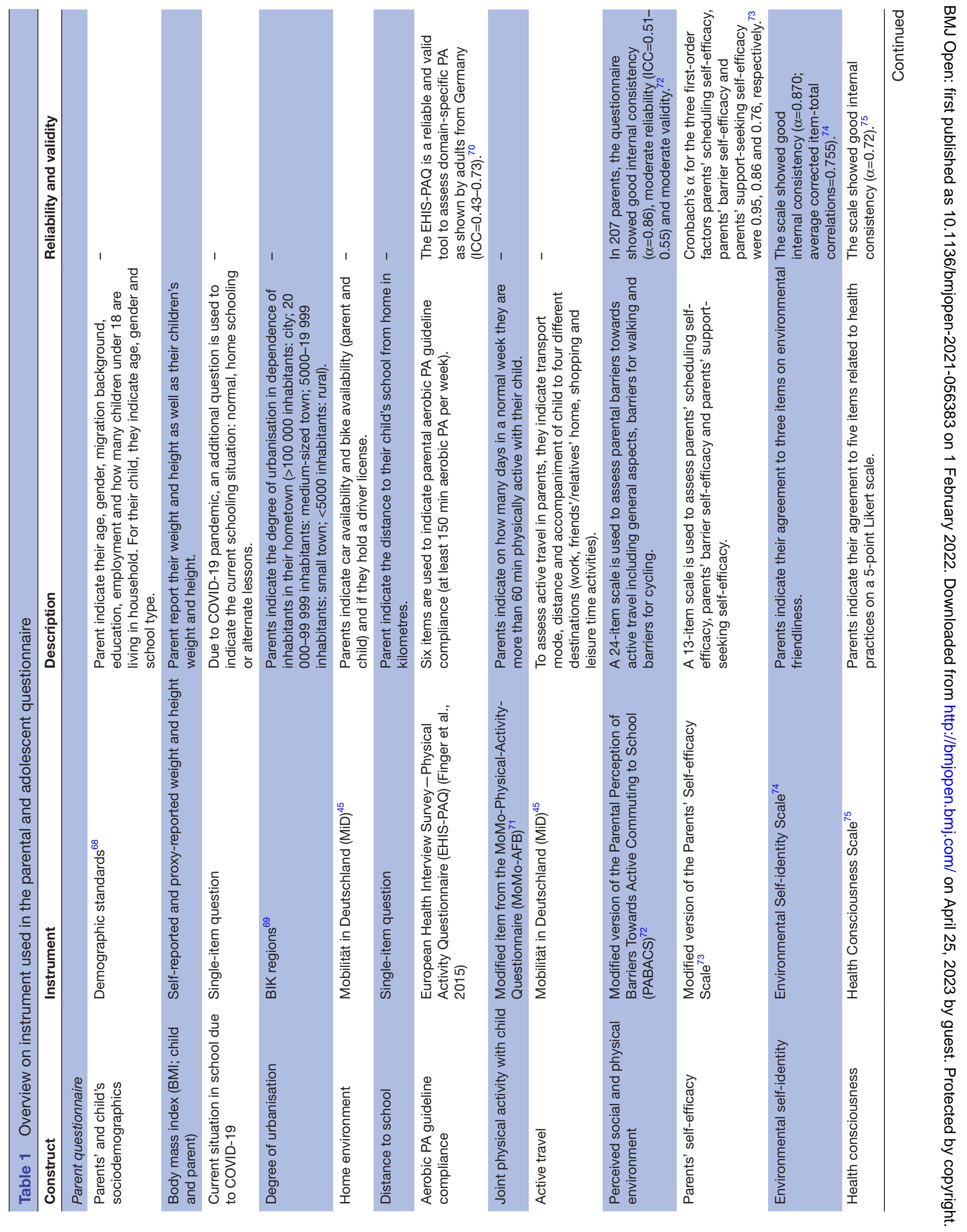




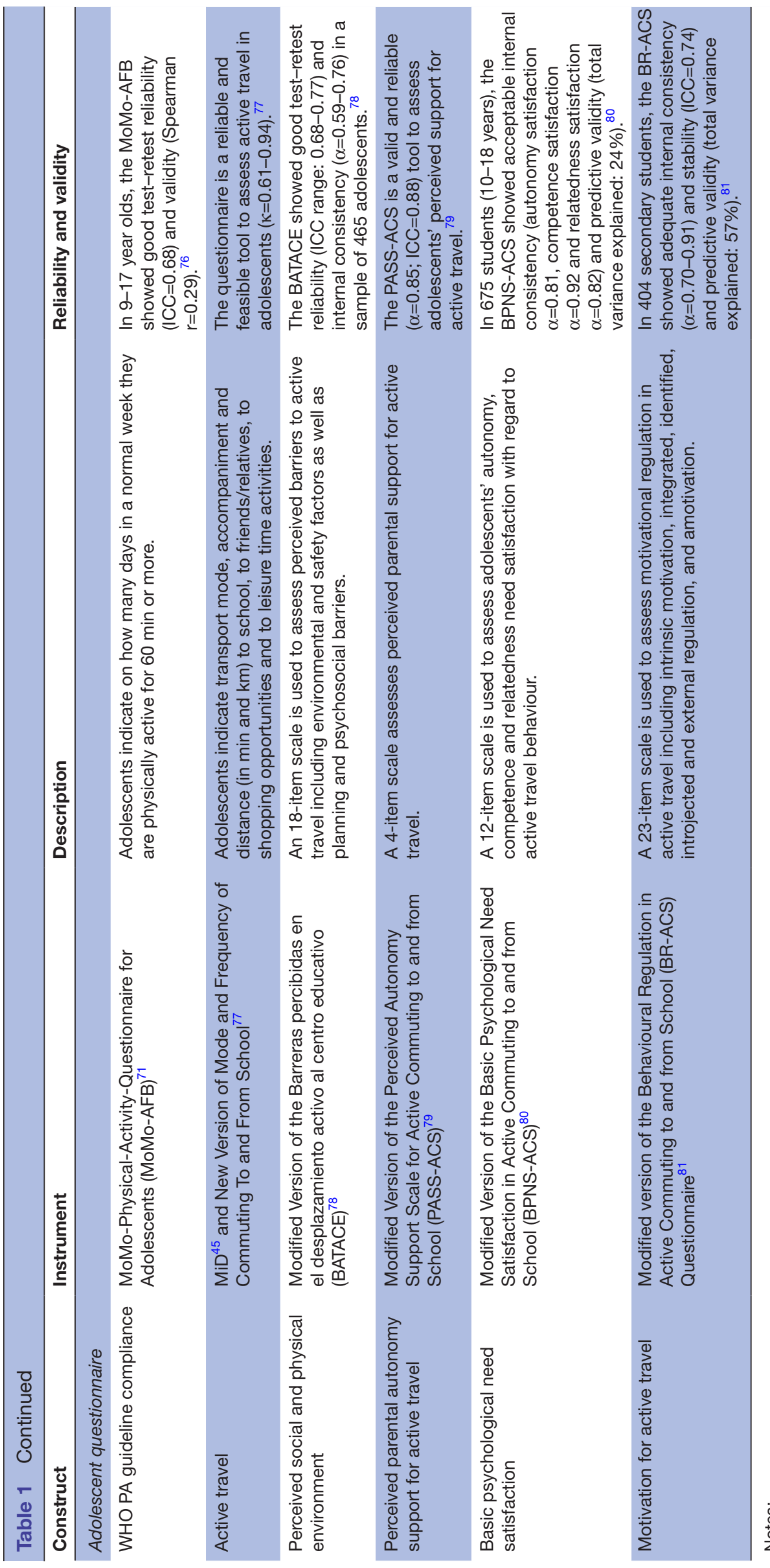

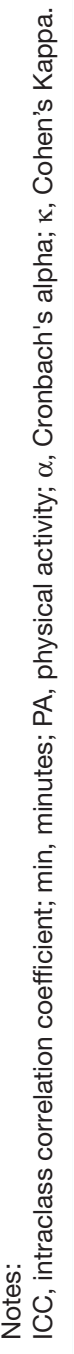


sex/gender differences. To assess associations between travel behaviour in adolescents and their parents, separate sex/gender analyses with parent-adolescent dyads (mother-daughter, mother-son, father-daughter and father-son) will be conducted by binary logistic regressions, with adolescents' travel behaviour as the outcome and parental travel modes as the predictors.

\section{Aim 3: comparing parental and adolescents' perspectives on transport mode choice}

To investigate parental and adolescents' perspectives on social and physical barriers of active travel, several multiple regression models will be performed. The overall score for transport mode in adolescents will be set as the dependent variable and each barrier as an independent variable. Thus, for each comparable barrier a separate multiple regression will be implemented.

Aim 4: investigating moderating effects of relevant socio-demographic characteristics

To assess whether the association between the social and physical environment and adolescents' travel behaviour are moderated by sociodemographic characteristics (eg, sex/gender, degree of urbanisation), we will run (1) logistic regression models controlling for sociodemographic variables, and (2) logistic regression analyses including interactions effects.

If appropriate, further exploratory analysis based on the theoretical framework will be conducted within the ARRIVE project. For all analysis, a level of $\alpha=0.05$ will be set as a threshold to determine statistical significance. Analyses will be conducted with R, Matlab and SPSS.

\section{Qualitative study \\ Aims}

The aim of the qualitative semistructured interviews will be to develop a deeper understanding of the decisionmaking processes relevant to adolescent transport mode choice (see figure 1, grey box). Accordingly, the qualitative interviews will seek to provide a nuanced understanding of transport mode choices by identifying novel concerns, preferences and values relevant to travel behaviour as articulated by the adolescents and parents themselves. To complement our online survey which aims to examine if and how various sociodemographic and socioenvironmental factors predict adolescent travel behaviour, this qualitative investigation seeks to understand the experiences of adolescent travel behaviour by precisely exploring what and why certain influences centrally impact parental and adolescent decision-making processes regarding transport mode choice. Specifically, the qualitative investigation will focus on the following research questions:

- What physical environment and individual factors influence transport mode choice in adolescents?

- How do adolescents experience the decision-making process on transport mode choice?
- How do parents experience the decision-making process on transport mode choice in adolescents?

- Are there any differences in adolescents' and parental perspectives on transport mode choice?

\section{Sampling strategy}

In addition to the online sample, we will also be recruiting another set of adolescents and their parents to take part in the qualitative investigation. These participants will be recruited using theoretical sampling methods. ${ }^{49}$ Therefore, the sample will not be defined by the onset of the study, but will be selected against the background of theoretical problems outlined earlier and in accordance with our proposed analysis processes. Our sampling methods will thus initially be based on ensuring the samples contain diversity with respect to socioeconomic status, migration status, sex/gender and environmental conditions (eg, urban and rural living locations). When possible, we will interview both parents to capture the perspectives of fathers and mothers. We anticipate that the final sample will consist of 10-15 adolescents and 15-20 parents.

\section{Data collection}

Interviews will be conducted with adolescent and parent participants separately. Prior to the data collection process, all interviewers received formal training from an interview expert. Sample interviews were conducted to ensure the appropriateness of the interview guides.

Interviews are anticipated to take around $30 \mathrm{~min}$ to complete. However, because deviations are possible, for each participant an appointment time of $60 \mathrm{~min}$ will be made. After giving informed consent and agreeing on an appointment, each participant will receive an individual link for an online meeting to conduct the interview. Participants will be able to complete their interview from any desired place so long as they have a stable internet connection and quiet surrounding. Before the start of the recording, the objective and the interview procedure will be explained and participants will be reassured of the voluntary nature of their involvement and their right to refuse to answer any questions. After clarifying any questions that participants may have, the audio recording device will be turned on and the interview will begin. At the end of the interview, the audio recording will stop.

\section{Interview guideline}

The focus of the interviews for both groups of participants will be the travel behaviour of adolescents and the associated decision-making process. During the interviews, adolescents and their parents will be encouraged to recount their travel experiences and their decisionmaking processes regarding mode choice in relation to four different situations. In order to generate a thorough understanding of the differences in decision-making processes when considering the choice of active versus passive transport to the distinct locations, different interview paths will be followed to ensure that the interview inquires about four (two active, two passive trips) 


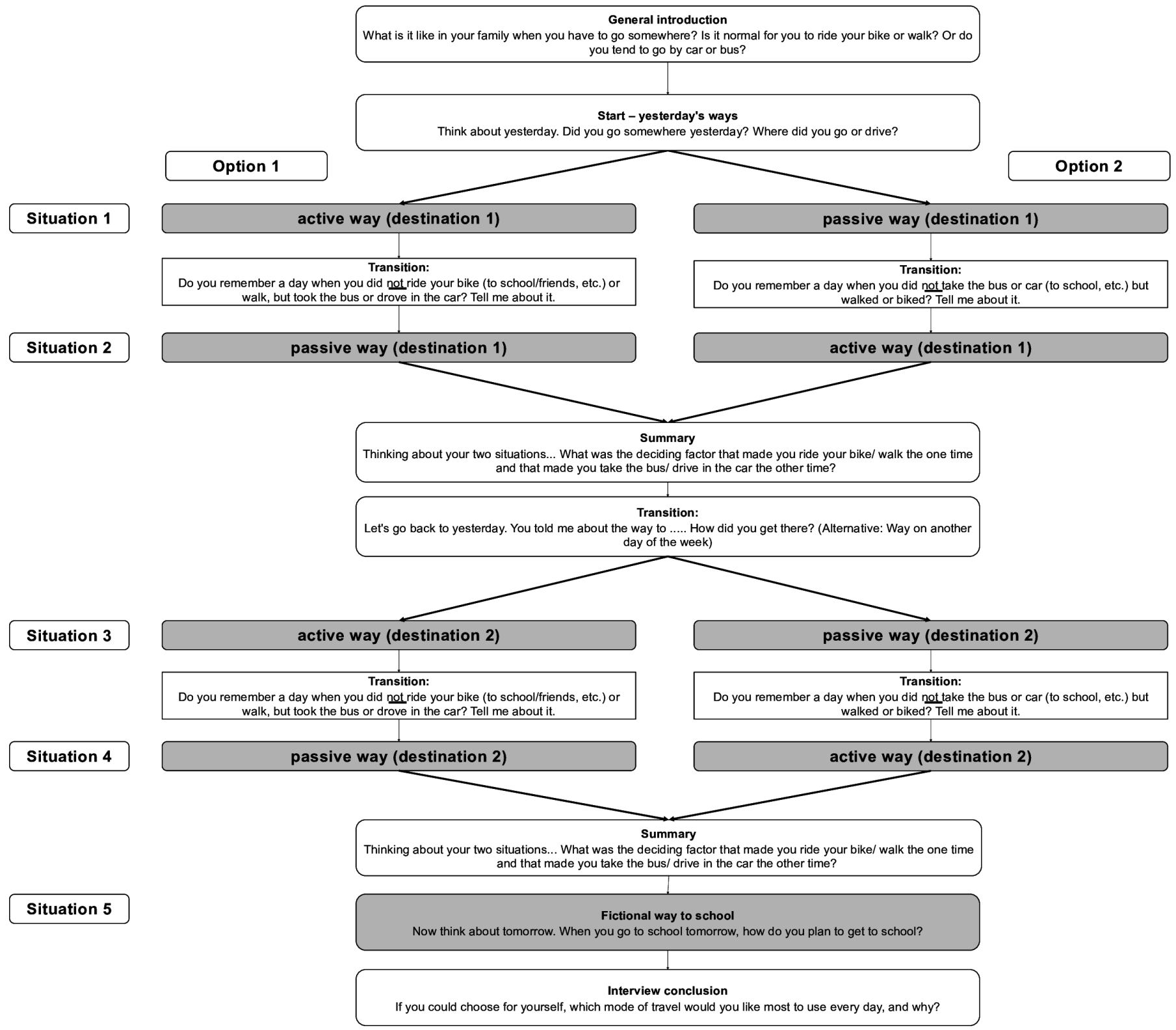

Figure 2 Structure of the interview guide-decision-tree.

different travel type-location examples (see figure 2). At the start of each interview, parents and adolescents will be instructed to first talk about a recent trip the latter made during one of the days prior to the interview. This first trip may be undertaken by either an active or passive means. Next, and to facilitate a comparison of factors affecting adolescent travel mode decision-making processes, participants will be asked to remember a trip to the same destination that they made using another transport mode (passive/active). To generate additional depth regarding understanding the potential variety of relevant factors influencing participants' decisionmaking processes, this procedure will be repeated for another destination that the adolescent travelled to in the previous week. In the event that an adolescent participant reports that they never changed transport mode to the two selected destinations, the interviewer will ask about any trips made with the opposite (passive/active) transport mode to explore how their habits and perceptions might be changed.

When discussing each of the four distinct trips, participants will be asked to describe their experiences of travelling in reference to a series of topics (see table 2). These topics are grouped into two blocks: the participant's situation at home (ie, conditions present before the adolescent's trip), and the situation on the journey itself (ie, social and environmental factors). To garner further information pertaining to the various circumstances which might affect the travel planning process, adolescents and parents will also be asked about a hypothetical commute to school, and specifically what factors (eg, concerns, priorities) they would foremost consider when planning the trip. Interviews will close with adolescents and parents being asked which transport mode they would prefer and 
Table 2 Topics addressed in the adolescents and parental interview

\begin{tabular}{|c|c|c|c|}
\hline & Situation & Topic & Examples \\
\hline \multirow[t]{3}{*}{$\begin{array}{l}\text { Active/passive transport } \\
\text { mode to destination }\end{array}$} & Situation at home & General aspects & $\begin{array}{l}\text { Eg, weather, stress, behaviour, } \\
\text { particularities }\end{array}$ \\
\hline & \multirow[t]{2}{*}{ Situation on the route } & Physical environment & $\begin{array}{l}\text { Eg, distance, characteristics of way, } \\
\text { like/dislike }\end{array}$ \\
\hline & & Social environment & Eg, friends, siblings, companionship \\
\hline \multirow[t]{2}{*}{ Hypothetical way to school } & \multirow[t]{2}{*}{ Situation at home } & Relevant factors & $\begin{array}{l}\text { Eg, weather, school situation, daily } \\
\text { schedule }\end{array}$ \\
\hline & & Decision-making process & $\begin{array}{l}\text { Eg, parental influence, motivation, } \\
\text { attitudes }\end{array}$ \\
\hline
\end{tabular}

why. More detailed information regarding both interview guides is enclosed in online supplemental material 1.

\section{Data analysis}

All audio recordings will be saved, treated as strictly confidential material and eventually transcribed verbatim. With regard to answering the four research questions noted earlier, analysis will be conducted using thematic analysis $^{50}$ or content analysis. ${ }^{51}$ In the first step, two researchers will independently analyse interview transcripts by the means of a deductive-inductive process. Deductive themes are defined prior to analysis according to the presented framework (figure 1) and in this study will include physical environment factors (eg, attractiveness, infrastructure, social environment), parent characteristics and attitudes (eg, socioeconomic status, social support), adolescent characteristics and attitudes (eg, age, motivation), and environmental perceptions (eg, parental perceptions of barriers/enablers, adolescent perceptions of barriers/enablers). To allow for more in-depth insights in the decision-making process, researchers will then code transcripts inductively to identify emerging ideas and concepts that may not align well with the original deductive categories. Subsequently, emerging differences and commonalities from the deductive-inductive analysis will be discussed together to develop consensus. In cases where a consensus may not be reached, a third researcher will join the discussion.

\section{Ethics and dissemination}

The ARRIVE study is designed in accordance with the ethical principles for research involving human subjects of the Declaration of Helsinki. Ethical approval for the study and its procedures were received from the ethics commission of the Friedrich-Alexander-University Erlangen-Nuremberg (Reg. 249_21 B). Participation in both parts of the study is voluntary. Participants will not receive any reimbursement or compensation for participating in one part of the study. Informed assent will be obtained from all adolescents and informed consent will be obtained from all parents that participate in this study.
With regard to the quantitative survey, no personally identifiable information will be included in the data set and transferred from forsa to the study team. In the interviews, participants will not be addressed by name, nor will any personal identifying information be requested. All data will be stored on central servers of the Technical University of Munich/Germany and the University of Erlangen-Nuremberg/Germany.

The results of the ARRIVE study will be disseminated through peer-review journal articles, particularly journals with international audiences, and will be presented at academic conferences. Additionally, the results of this study will be disseminated to relevant stakeholders, and policy makers, as well as be made publicly available for interested individuals, families, teachersand caregivers via a project website and public knowledge translation activities (eg, public talks, community information sessions).

\section{Patient and public involvement statement}

No medical patients and/or members of the public were involved in setting the research question nor they were involved in developing plans for design (or implementation) of this study protocol.

\section{DISCUSSION}

Increasing physical activity in adolescents is an immediate and serious challenge for modern societies, but one that if effectively addressed can contribute to preventing a number of chronic and non-communicable diseases. ${ }^{7}$ Recent recommendations by the European Society of Cardiology (ESC) suggest approaches targeting optimising lifestyle activities to change physical activity behaviours and reduce sedentary time as important preventive measures in this regard. $^{52}$ Better understanding the decision-making processes of both adolescents and parents regarding multiple forms of, and influences on, daily adolescent active travel behaviour can be an effective strategy in supporting these desired lifestyle activity alterations. 
Until now, only a few qualitative studies exist that provide a deeper understanding of the inter-relationships and familial decision-making processes on active travel behaviour in adolescents. ${ }^{28} 2932$ The inclusion of qualitative methods in the study of this issue can be beneficial as they may help to capture, reconstruct and comprehend the social reality of groups or individuals as they focus on the experiences, meanings and perspectives of the participants. ${ }^{53}$ Additionally, previous evidence has posited that child or adolescent sex/gender plays a significant role with regard to physical activity and travel behaviour, ${ }^{54-56}$ it has been observed that parental perspectives of this issue have been largely limited to the views of mothers $\left(\right.$ eg, $\left.{ }^{29}{ }^{57}\right)$.

The ARRIVE study aims to address these research gaps, by providing a comprehensive multicomponent and multigroup analysis of the socioecological determinants of adolescent active travel behaviour and its associated decision-making processes. Quantitative analyses of several theoretically relevant predictors of adolescent active travel are intended to provide the necessary empirical evidence to illustrate the relationships of the family environment with non-school commutes and travel behaviours. Qualitative semistructured interviews are anticipated to provide deeper insights into the decisionmaking processes of both adolescents and parents regarding travel mode behaviours. Together, the findings from both components of the ARRIVE study should be of value to both practitioners and researchers as they will offer a comprehensive evaluation of a more diverse set of trips, family predictors and decision-making processes associated with adolescent active travel, as well as provide empirical evidence to support public health active travel interventions for targeted adolescent groups and families.

To build on the expected findings of the ARRIVE study in future research, targeted active travel interventions, especially those featuring gamification elements,${ }^{58}$ could be a starting point for larger-scale prevention efforts aimed to reduce non-communicable diseases and to improve public health. For example, longitudinal data support that 9-18-year-old active commuters have higher levels of physical activity during young adulthood and can maintain these behaviours for up to 12 years, ${ }^{59}$ thus targeted and gamified early-years interventions may be prudent prevention strategies. Other potential benefits of regular active travel, or targeted interventions, include the improved emotional health and happiness of both adolescents and adults ${ }^{60}$ improvements in cardiovascular health (eg, exercise capacity, maximal power, blood pressure and blood parameters) in adults ${ }^{61-63}$ and adolescents $^{6465}$ and cleaner and less congested neigbourhoods $^{66}{ }^{67}$-all points which future intervention studies could also evaluate alongside the findings (eg, articulated decision-making processes) of our ARRIVE study.

Contributors AKR, IM, FB, EE, DR, CK and YD made substantial contribution to the concept and design of the ARRIVE study. AKR and IM prepared the first draft of the protocol article and finalised the manuscript. FB, EE, DR, AB, CK and YD made substantial contributions to the manuscript, provided edits to the manuscript and read and approved the final manuscript.

Funding We acknowledge financial support by Deutsche Forschungsgemeinschaft and Friedrich-Alexander-Universität Erlangen-Nürnberg within the funding programme "Open Access Publication Funding".

Competing interests None declared.

Patient consent for publication Not applicable.

Provenance and peer review Not commissioned; externally peer reviewed.

Supplemental material This content has been supplied by the author(s). It has not been vetted by BMJ Publishing Group Limited (BMJ) and may not have been peer-reviewed. Any opinions or recommendations discussed are solely those of the author(s) and are not endorsed by BMJ. BMJ disclaims all liability and responsibility arising from any reliance placed on the content. Where the content includes any translated material, BMJ does not warrant the accuracy and reliability of the translations (including but not limited to local regulations, clinical guidelines, terminology, drug names and drug dosages), and is not responsible for any error and/or omissions arising from translation and adaptation or otherwise.

Open access This is an open access article distributed in accordance with the Creative Commons Attribution Non Commercial (CC BY-NC 4.0) license, which permits others to distribute, remix, adapt, build upon this work non-commercially, and license their derivative works on different terms, provided the original work is properly cited, appropriate credit is given, any changes made indicated, and the use is non-commercial. See: http://creativecommons.org/licenses/by-nc/4.0/.

ORCID iDs

Anne Kerstin Reimers http://orcid.org/0000-0003-4053-1378

Franziska Beck http://orcid.org/0000-0002-6360-8828

\section{REFERENCES}

1 WHO. Who guidelines on physical activity and sedentary behaviour. Geneva: World Health Organization, 2020.

2 Janssen I, Leblanc AG. Systematic review of the health benefits of physical activity and fitness in school-aged children and youth. Int $J$ Behav Nutr Phys Act 2010;7:40.

3 Poitras VJ, Gray CE, Borghese MM, et al. Systematic review of the relationships between objectively measured physical activity and health indicators in school-aged children and youth. Appl Physiol Nutr Metab 2016;41:S197-239.

4 Warburton DER, Charlesworth S, Ivey A, et al. A systematic review of the evidence for Canada's Physical Activity Guidelines for Adults. Int $J$ Behav Nutr Phys Act 2010;7:39.

5 Guthold R, Stevens GA, Riley LM, et al. Global trends in insufficient physical activity among adolescents: a pooled analysis of 298 population-based surveys with 1.6 million participants. Lancet Child Adolesc Health 2020;4:23-35.

6 Guthold R, Stevens GA, Riley LM, et al. Worldwide trends in insufficient physical activity from 2001 to 2016: a pooled analysis of 358 population-based surveys with 1.9 million participants. Lancet Glob Health 2018:6:e1077-86.

7 WHO. Global action plan on physical activity 2018-2030: more active people for a healthier world. Geneva: World Health Organization, 2018.

8 Chillón P, Ortega FB, Ruiz JR, et al. Active commuting to school in children and adolescents: an opportunity to increase physical activity and fitness. Scand J Public Health 2010;38:873-9.

9 Reimers AK, Marzi I, Schmidt SCE, et al. Trends in active commuting to school from 2003 to 2017 among children and adolescents from Germany: the MoMo study. Eur J Public Health 2021;31:373-8.

10 Smith M, Ikeda E, Duncan S, et al. Trends and measurement issues for active transportation in New Zealand's physical activity report cards for children and youth. Journal of Transport \& Health 2019;15:100789.

11 McDonald NC. Active transportation to school: trends among U.S. schoolchildren, 1969-2001. Am J Prev Med 2007;32:509-16.

12 Grize L, Bringolf-Isler B, Martin E, et al. Trend in active transportation to school among Swiss school children and its associated factors: three cross-sectional surveys 1994, 2000 and 2005. Int J Behav Nutr Phys Act 2010;7:28.

13 Pavelka J, Sigmundová D, Hamř́k Z, et al. Trends in active Commuting to school among Czech schoolchildren from 2006 to 2014. Cent Eur J Public Health 2017;25 Suppl 1:S21-5.

14 Schönbach DMI, Brindley C, Reimers AK, et al. Socio-Demographic correlates of cycling to school among 12- to 15-year olds in southern Germany. Int J Environ Res Public Health 2020;17:9269. 
15 Reimers AK, Jekauc D, Peterhans E, et al. Prevalence and sociodemographic correlates of active commuting to school in a nationwide representative sample of German adolescents. Prev Med 2013:56:64-9.

16 Trang NHHD, Hong TK, Dibley MJ. Active commuting to school among adolescents in Ho Chi Minh City, Vietnam: change and predictors in a longitudinal study, 2004 to 2009. Am J Prev Med 2012;42:120-8.

17 Van Dyck D, De Bourdeaudhuij I, Cardon G, et al. Criterion distances and correlates of active transportation to school in Belgian older adolescents. Int J Behav Nutr Phys Act 2010;7:87.

18 Pont K, Ziviani J, Wadley D, et al. Environmental correlates of children's active transportation: A systematic literature review. Health Place 2009;15:849-62.

19 Marques A, Peralta M, Sarmento H. Personal and behavioral correlates of active Commuting among adolescents. Montenegrin Journal of Sports Science and Medicine 2016;5:29-34.

20 Martínez-Gómez D, Veiga OL, Gomez-Martinez S, et al. Behavioural correlates of active commuting to school in Spanish adolescents: the AFINOS (physical activity as a preventive measure against overweight, obesity, infections, allergies, and cardiovascular disease risk factors in adolescents) study. Public Health Nutr 2011;14:1779-86.

21 Yang L, Griffin S, Khaw KT. Longitudinal associations between built environment characteristics and changes in active commuting. BMC Public Health 2017;17:8.

22 Panter J, Corder K, Griffin SJ, et al. Individual, socio-cultural and environmental predictors of uptake and maintenance of active commuting in children: longitudinal results from the speedy study. Int $J$ Behav Nutr Phys Act 2013;10:83.

23 Sallis JF, Owen N, Fisher EB. Ecological models of health behavior. In: Health behavior and health education: theory, research, and practice. 4th edn. San Francisco, Calif: Jossey-Bass, 2008.

24 Zaragoza J, Corral A, Ikeda E, et al. Assessment of psychological, social cognitive and perceived environmental influences on children's active transport to school. Journal of Transport \& Health 2020;16:100839.

25 Pont K, Ziviani J, Wadley D, et al. The model of children's active travel (M-CAT): a conceptual framework for examining factors influencing children's active travel. Aust Occup Ther $J$ 2011:58:138-44.

26 Götschi T, Kahlmeier S, Castro A, et al. Integrated impact assessment of active travel: expanding the scope of the health economic assessment tool (heat) for walking and cycling. Int $J$ Environ Res Public Health 2020;17. doi:10.3390/ijerph17207361. [Epub ahead of print: 0910 2020].

27 Panter JR, Jones AP, van Sluijs EM. Environmental determinants of active travel in youth: a review and framework for future research. Int $J$ Behav Nutr Phys Act 2008;5:34.

28 Faulkner GEJ, Richichi V, Buliung RN, et al. What's "quickest and easiest?": parental decision making about school trip mode. Int $J$ Behav Nutr Phys Act 2010;7:11:62.

29 Forsberg H, Rutberg S, Mikaelsson K, et al. It's about being the good parent: exploring attitudes and beliefs towards active school transportation. Int J Circumpolar Health 2020;79:1798113.

30 Francis J, Martin K, Wood L, et al. 'I'll be driving you to school for the rest of your life': A qualitative study of parents' fear of stranger danger. J Environ Psychol 2017;53:112-20.

31 Ikeda E, Hinckson E, Witten K, et al. Associations of children's active school travel with perceptions of the physical environment and characteristics of the social environment: a systematic review. Health Place 2018:54:118-31.

32 Westman J, Friman M, Olsson LE. What Drives Them to Drive? Parents' Reasons for Choosing the Car to Take Their Children to School. Front Psychol 2017;8.

33 Nobis C, Kuhnimhof T. Mobilität in Deutschland - mid Ergebnisbericht. studie von infas, DLR, IVT und infas $360 \mathrm{Im}$ Auftrag des Bundesministers für Verkehr und digitale Infrastruktur (FE-Nr. 70.904/15. Bonn, Berlin, 2018. www.mobilitaet-in-deutschland.de;

34 Aranda-Balboa MJ, Huertas-Delgado FJ, Herrador-Colmenero M, et al. Parental barriers to active transport to school: a systematic review. Int J Public Health 2020;65:87-98.

35 Lu W, McKyer ELJ, Lee C, et al. Perceived barriers to children's active commuting to school: a systematic review of empirical, methodological and theoretical evidence. Int J Behav Nutr Phys Act 2014; $11: 140$

36 Niermann CYN, Gerards SMPL, Kremers SPJ. Conceptualizing family influences on children's energy Balance-Related behaviors: levels of interacting family environmental subsystems (the LIFES framework). Int J Environ Res Public Health 2018:15. doi:10.3390/ ijerph15122714. [Epub ahead of print: 0112 2018].
37 Niermann CYN, Kremers SPJ, Renner B, et al. Family health climate and adolescents' physical activity and healthy eating: a crosssectional study with Mother-Father-Adolescent triads. PLoS One 2015;10:e0143599.

38 Tabak I, Mazur J, Nałęcz H. Family and individual predictors and mediators of adolescent physical activity. Health Psychology Report 2017;4:333-44.

39 Faulkner G, Mitra R, Buliung R, et al. Children's outdoor playtime, physical activity, and parental perceptions of the neighbourhood environment. Int J Play 2015;4:84-97.

40 Aranda-Balboa MJ, Chillón P, Saucedo-Araujo RG, et al. Children and parental barriers to active Commuting to school: a comparison study. Int J Environ Res Public Health 2021;18. doi:10.3390/ ijerph18052504. [Epub ahead of print: 0303 2021].

41 Christian HE, Klinker CD, Villanueva K, et al. The effect of the social and physical environment on children's independent mobility to neighborhood destinations. J Phys Act Health 2015;12 Suppl 1:S84-93.

42 Kyttä M, Oliver M, Ikeda E, et al. Children as urbanites: mapping the affordances and behavior settings of urban environments for Finnish and Japanese children. Children's Geographies 2018;16:319-32.

43 Veitch J, Carver A, Salmon J, et al. What predicts children's active transport and independent mobility in disadvantaged neighborhoods? Health Place 2017;44:103-9.

44 Bujang MA, Sa'at N, Sidik TMITAB, Sidik T, et al. Sample size guidelines for logistic regression from observational studies with large population: emphasis on the accuracy between statistics and parameters based on real life clinical data. Malays $J$ Med Sci 2018;25:122-30

45 Eggs J, Follmer R, Gruschwitz D. Mobilität in Deutschland - MiD Methodenbericht. Studie vom infas, DLR, IVT und infas $360 \mathrm{im}$ Auftrag des Bundesministers für Verkehr und digitale Infrastruktur. Bonn, Berlin, 2018. www.mobilität-in-deutschland.de;

46 Villanueva K, Giles-Corti B, Bulsara M, et al. Does the walkability of neighbourhoods affect children's independent mobility, independent of parental, socio-cultural and individual factors? Children's Geographies 2014;12:393-411.

47 Blanz M. Forschungsmethoden und Statistik für die Soziale Arbeit: Grundlagen und Anwendungen Kohlhammer Verlag, 2021.

48 Beasley TM, Schumacker RE. Multiple regression approach to analyzing contingency tables: post hoc and planned comparison procedures. The Journal of Experimental Education 1995;64:79-93.

49 Nagl-Cupal M. Theoretical sampling. ProCare 2013;18:20-2.

50 Braun V, Clarke V. Using thematic analysis in psychology. Qual Res Psychol 2006;3:77-101.

51 Mayring P, Fenzl T. Qualitative Inhaltsanalyse. Handbuch - Methoden der empirischen Sozialforschung. Springer, 2019: 633-48.

52 Visseren FLJ, Mach F, Smulders YM. 2021 ESC guidelines on cardiovascular disease prevention in clinical practice: developed by the task force for cardiovascular disease prevention in clinical practice with representatives of the European Society of cardiology and 12 medical societies with the special contribution of the European association of preventive cardiology (EAPC). Eur Heart $J$ 2021;42:3227-337.

53 Hammarberg K, Kirkman M, de Lacey S. Qualitative research methods: when to use them and how to judge them. Hum Reprod 2016;31:498-501.

54 Sigmundová D, Sigmund E, Badura P, et al. Parent-Child physical activity association in families with 4-to 16-year-old children. Int $J$ Environ Res Public Health 2020;17. doi:10.3390/ijerph17114015. [Epub ahead of print: 0506 2020].

55 Reimers AK, Boxberger K, Schmidt SCE, et al. Social support and modelling in relation to physical activity participation and outdoor play in preschool children. Children 2019;6:115.

56 Rodriguez-Rodriguez F, Huertas-Delgado FJ, Barranco-Ruiz Y. Are the Parents' and Their Children's Physical Activity and Mode of Commuting Associated? Analysis by Gender and Age Group. Int J Environ Res Public Health 2020;17.

57 Huertas-Delgado FJ, Herrador-Colmenero M, Villa-González E, et al. Parental perceptions of barriers to active commuting to school in Spanish children and adolescents. Eur J Public Health 2017;27:416-21.

58 BTH Y, Mulley C, Burke M. Gamification in transport interventions: another way to improve travel behavioural change. Cities 2019;85:140-9 https://ses.library.usyd.edu.au/handle/2123/19093

59 Yang X, Telama R, Hirvensalo M, et al. Active commuting from youth to adulthood and as a predictor of physical activity in early midlife: the young Finns study. Prev Med 2014;59:5-11.

60 Ramanathan S, O'Brien C, Faulkner G, et al. Happiness in motion: emotions, well-being, and active school travel. J Sch Health 2014;84:516-23. 
61 Schäfer C, Mayr B, Fernandez La Puente de Battre MD, et al. Health effects of active commuting to work: the available evidence before GISMO. Scand J Med Sci Sports 2020;30 Suppl 1:8-14

62 Mueller N, Rojas-Rueda D, Cole-Hunter T, et al. Health impact assessment of active transportation: a systematic review. Prev Med 2015;76:103-14.

$63 \mathrm{Xu} \mathrm{H}$, Wen LM, Rissel C. The relationships between active transport to work or school and cardiovascular health or body weight: a systematic review. Asia Pac J Public Health 2013;25:298-315.

64 Chillón P, Ortega FB, Ruiz JR, et al. Active commuting to school in children and adolescents: an opportunity to increase physical activity and fitness. Scand J Public Health 2010;38:873-9.

65 Lubans DR, Boreham CA, Kelly P, et al. The relationship between active travel to school and health-related fitness in children and adolescents: a systematic review. Int J Behav Nutr Phys Act 2011;8:5.

66 Brand C, Dons E, Anaya-Boig E, et al. The climate change mitigation effects of daily active travel in cities. Transp Res $D$ Transp Environ 2021;93:102764

67 Giles-Corti B, Foster S, Shilton T, et al. The co-benefits for health of investing in active transportation. N S W Public Health Bull 2010;21:122-7.

68 Statistisches Bundesamt. Statistik und Wirtschaft - Demographische Standards. Wiesbaden: Statistisches Bundesamt, 2016.

69 Behrens K, Böltken F, Dittmar H. Regionale standards: Ausgabe 2019. Köln, 2019.

70 Baumeister SE, Ricci C, Kohler S, et al. Physical activity surveillance in the European Union: reliability and validity of the European health interview Survey-Physical activity questionnaire (EHIS-PAQ). Int $J$ Behav Nutr Phys Act 2016;13:61.

71 Schmidt SCE, Will N, Henn A. Der Motorik-Modul Aktivitätsfragebogen MoMo-AFB : Leitfaden zur Anwendung und Auswertung, 2016.

72 Huertas-Delgado FJ, Molina-García J, Van Dyck D, et al. A questionnaire to assess parental perception of barriers towards active commuting to school (PABACS): reliability and validity. $J$ Transp Health 2019;12:97-104.
73 Lu W, McKyer ELJ, Lee C, et al. Children's active commuting to school: an interplay of self-efficacy, social economic disadvantage, and environmental characteristics. International Journal of Behavioral Nutrition and Physical Activity 2015;12:29.

74 Fallah Zavareh M, Mehdizadeh M, Nordfjærn T. Active travel as a pro-environmental behaviour: an integrated framework. Transportation Research Part D: Transport and Environment 2020;84:102356.

75 Dutta-Bergman MJ. Primary sources of health information: comparisons in the domain of health attitudes, health cognitions, and health behaviors. Health Commun 2004;16:273-88.

76 Jekauc D, Wagner MO, Kahlert D, et al. Reliabilität und Validität des MoMo-Aktivitätsfragebogens für Jugendliche (MoMo-AFB) Diagnostica 2013;59:100-11.

77 Segura-Díaz JM, Rojas-Jiménez Álvaro, Barranco-Ruiz Y, et al. Feasibility and reliability of a questionnaire to assess the mode, frequency, distance and time of Commuting to and from school: the PACO study. Int J Environ Res Public Health 2020;17. doi:10.3390/ ijerph17145039. [Epub ahead of print: 1307 2020].

78 Molina-García J, Queralt A, Estevan I, et al. [Perceived barriers to active commuting to school: reliability and validity of a scale]. Gac Sanit 2016;30:426-31.

79 Burgueño R, González-Cutre D, Sevil-Serrano J, et al. Psychometric properties of the teachers', parents' and peers' versions of the Perceived Autonomy Support Scale for Active Commuting to and from School (PASS-ACS) in children and adolescents. Travel Behaviour and Society 2020;20:322-30.

80 Burgueño R, González-Cutre D, Sevil-Serrano J, et al. Validation of the basic psychological need satisfaction in active Commuting to and from school (BPNS-ACS) scale in Spanish young people. $J$ Transp Health 2020;16:100825.

81 Burgueño R, González-Cutre D, Sevil-Serrano J, et al. Understanding the motivational processes involved in adolescents' active commuting behaviour: Development and validation of the Behavioural Regulation in Active Commuting to and from School (BR-ACS) Questionnaire. Transp Res Part F Traffic Psychol Behav 2019;62:615-25. 